\title{
Periodontal Repair in Dogs: Evaluation of a Bioabsorbable Space-Providing Macro- Porous Membrane with Recombinant Human Bone Morphogenetic Protein-2
}

Ulf M.E. Wikesjö, ${ }^{* \dagger}$ Won Hee Lim, ${ }^{\dagger}$ Robert C. Thomson, ${ }^{\dagger}$ Alonzo D. Cook, ${ }^{\dagger}$ John M. Wozney, ${ }^{\S}$ and W. Ross Hardwick ${ }^{\ddagger}$

Background: Recombinant human bone morphogenetic protein-2 (rhBMP-2) technologies have been shown to significantly support alveolar bone formation. Biomaterial limitations, however, have restricted the biologic potential for onlay indications. The objective of this study was to evaluate regeneration of alveolar bone and periodontal attachment, and biomaterials reaction following surgical implantation of a spaceproviding, bioabsorbable, macroporous, polyglycolic acid-trimethylene carbonate (PGA-TMC) membrane combined with a rhBMP-2 construct in a discriminating onlay defect model.

Methods: Routine supraalveolar periodontal defects were created at the mandibular premolar teeth in 9 beagle dogs. Contralateral jaw quadrants in subsequent animals were randomly assigned to receive the domeshaped PGA-TMC (100 to $120 \mu \mathrm{m}$ pores) membrane with rhBMP-2 $(0.2 \mathrm{mg} / \mathrm{mL}$ ) in a bioresorbable hyaluronan (Hy) carrier or the PGA-TMC membrane with Hy alone (control). The gingival flaps were advanced to submerge the membranes and teeth and sutured. Animals were euthanized at 8 and 24 weeks postsurgery for histologic observations.

Results: Jaw quadrants receiving the PGA-TMC membrane alone experienced exposures at various time points throughout the study. Jaw quadrants receiving the PGA-TMC/rhBMP-2 combination remained intact, although one site experienced a late minor exposure. Newly formed alveolar bone approached and became incorporated into the macroporous PGA-TMC membrane in sites receiving rhBMP-2. The PGA-TMC biomaterial was occasionally associated with a limited inflammatory reaction. Residual PGA-TMC could not be observed at 24 weeks postsurgery. Residual Hy could not be observed at any time interval. Regeneration of alveolar bone height (means \pm SD) was significantly increased in sites receiving the PGA-TMC/rhBMP 2 combination compared to control $(3.8 \pm 1.3$ versus $0.7 \pm 0.5 \mathrm{~mm}$ at 8 weeks and $4.6 \pm 0.8$ versus $2.1 \pm$ $0.4 \mathrm{~mm}$ at 24 weeks; $P<0.05)$. Limited cementum regeneration was observed for PGA-TMC/rhBMP-2 and PGA-TMC control sites. Ankylosis compromised regeneration in sites receiving PGA-TMC/rhBMP-2.

Conclusions: The bioabsorbable, space-providing, macroporous PGA-TMC membrane appears to be a compatible biomaterial for bone augmentation procedures. rhBMP-2 significantly enhances alveolar bone augmentation and soft tissue healing when combined with the PGA-TMC membrane. J Periodontol 2003; 74:635-647.

\section{KEY WORDS}

Alveolar ridge augmentation; animal studies; bone regeneration; membranes, barrier; membranes, bioabsorbable; periodontal attachment; wound healing.

* Laboratory for Applied Periodontal and Craniofacial Regeneration, Temple University School of Dentistry, Philadelphia, PA

$\dagger$ Department of Periodontology, Temple University School of Dentistry.

\# W.L. Gore \& Associates, Inc., Flagstaff, AZ.

$\S$ Wyeth Research, Cambridge, MA. 
$\mathrm{D}$ esign criteria for guided tissue/bone regeneration (GTR/GBR) devices include biocompatibility, cell/tissue occlusion, space maintenance, tissue integration, and ease of use. ${ }^{1,2}$ Studies have shown that regeneration of alveolar bone is critically dependent on space provision by the tissue occlusive GTR or GBR devices (references 3 through 7 and unpublished data). Limited or no regeneration of alveolar bone is observed in supraalveolar periodontal defects and in alveolar ridge defects following gingival flap surgery without a space providing GTR/GBR device, when the device inadvertently had collapsed or had been compressed into the defect, or when the space underneath the membrane during surgery had been filled with slowly resorbing or non-resorbable biomaterial in an attempt to enhance space provision (references 3 through 7 and unpublished data).

Karaki et al. ${ }^{8}$ evaluated the influence of space provision without connective tissue occlusion on osteogenesis. Contralateral horizontal periodontal defects were surgically created between the mandibular premolar teeth in dogs. A tissue-expanding gold mesh was applied on one side while the contralateral side served as surgical control. Callus formation was enhanced in defects treated with the gold mesh compared to the surgical control. Evidently, osteogenesis in a periodontal environment may proceed in presence of space provision without strict provisions for gingival tissue occlusion. A concept of space provision without tissue occlusion for alveolar regeneration emerges from this study. This concept is supported by observations from a more recent study reporting the influence of biomaterials characteristics on bone healing in the craniofacial skeleton; i.e., the influence of expanded polytetrafluoroethylene (ePTFE) barrier porosity on osteogenesis. ${ }^{9}$ In a rat calvaria model, ePTFE barrier devices with a porosity of 20 to 25 and $100 \mu \mathrm{m}$ increased the rate of osteogenesis compared to less porous devices $(<8 \mu \mathrm{m})$. The authors proposed that increased permeability allowing transposition of extracellular matrix and cellular elements favored osteogenesis.

Most recently a non-resorbable, macroporous ( $300 \mu \mathrm{m}$ pores, $0.8 \mathrm{~mm}$ apart) ePTFE membrane was used in a proof-of-principle study designed to test the concept of tissue occlusivity for GTR. ${ }^{10}$ It was shown that tissue occlusivity was not a critical requirement for GTR. Clinically relevant amounts of alveolar bone and cementum regeneration with functionally inserting fibers were demonstrated following installation of tissue occlusive and non-occlusive space providing macroporous ePTFE devices. It was also shown that the macroporous ePTFE device was considerably more clinically effective than the occlusive device. None of the sites receiving the macroporous device experienced wound failure in contrast to $50 \%$ of the sites receiving the occlusive ePTFE device. Wound failure, membrane exposure, contamination, and infection are not uncommon following use of tissue occlusive GTR devices in the clinic and commonly compromise clinical outcomes following GTR (references 3 through 5, 10 through 13, and unpublished data). Taken together, these observations suggest that macroporous devices may prove clinically beneficial in GTR.

In clinical practice, non-resorbable devices require surgical removal upon completion of regenerative treatment, which causes an added inconvenience to the patient and clinician. Macroporous devices for GTR must use bioabsorbable biomaterials because the porous nature of the device results in considerable tissue integration, which may make surgical removal of a nonresorbable device complicated and result in considerable morbidity. To circumvent the need for surgical removal, resorbable biomaterials for GTR have been suggested, evaluated, and manufactured for clinical use. Natural products like collagen-based devices; dura mater; cargile membrane; oxidized cellulose; laminar bone; and synthetic bioabsorbable devices based on polylactic acid, polyglycolic acid, and their copolymers have been developed and marketed for the treatment of patients. ${ }^{14}$ While bioabsorbable devices do not require a second surgery, they commonly present limitations including space provision, early/late resorption, and adverse inflammatory reactions in their resorption process resulting in fragmentation and associated foreign body reactions. Recently, Tatakis and Trombelli ${ }^{15}$ reported abscess formation including foamy macrophages in over $50 \%$ of a group of patients treated with GTR using a DL-polylactic acid based device. Thus, it appears critical that biomaterials developed for clinical use receive considerable scrutiny in relevant, discriminating preclinical models prior to clinical release.

Other studies have evaluated bone morphogenetic proteins (BMPs) as a candidate therapy for alveolar augmentation and periodontal regeneration. rhBMP-2 technologies have been shown to significantly increase bone regeneration in craniofacial applications (references 16 through 21 and unpublished data). However, limitations of rhBMP-2 technologies have been reported relative to biomaterials evaluated as carriers. ${ }^{21-25}$ In particular, carrier limitations have restricted the biologic potential of rhBMP2 for indications where soft tissue compressive forces may limit the space for bone formation. ${ }^{22-25}$ The objective of this study was to evaluate a space-providing, macroporous, bioabsorbable polyglycolic acid-trimethylene carbonate membrane intended for GTR and to evaluate this bioabsorbable device in presence of rhBMP-2 induced bone in a discriminating preclinical onlay defect model.

\section{MATERIALS AND METHODS}

\section{Animals}

Nine male beagle dogs (age 18 to 24 months, weight approximately $15 \mathrm{~kg}$ ) exhibiting intact mandibular pre- 
molar dentition without crowding or evidence of periodontal disease, obtained from an approved dealer, were used. Animal selection and management, surgery protocol, and periodontal defect preparation followed routines approved by the Animal Care and Use Committee, W.L. Gore $\mathcal{E}$ Associates, Inc., Flagstaff, Arizona. The animals were identified by an implanted microchip. The animals had access to standard laboratory diet and water until the beginning of the study. Oral prophylaxis was performed within 2 weeks prior to the experimental surgeries.

\section{Macroporous GTR Device}

A bioabsorbable, space-providing, macroporous, polyglycolic acid-trimethylene carbonate membrane (PGA-TMC) was used (Fig. 1). The devices incorporated a proprietary fibrous non-woven construction designed to integrate with the host tissue during healing. In addition, 100 to $120 \mu \mathrm{m}$ through-and-through holes were laser-etched in the devices to allow fibrovascular penetration into to the space created by the device when implanted. Device configuration was custommade to adapt specifically to the experimental model and to be sufficiently rigid to resist collapse from overlying tissue pressure. This macroporous PGA-TMC material has been shown to be biocompatible. ${ }^{26}$ Experimental studies have shown membrane configurations based on this biomaterial to support periodontal regeneration and alveolar bone augmentation. ${ }^{14}$
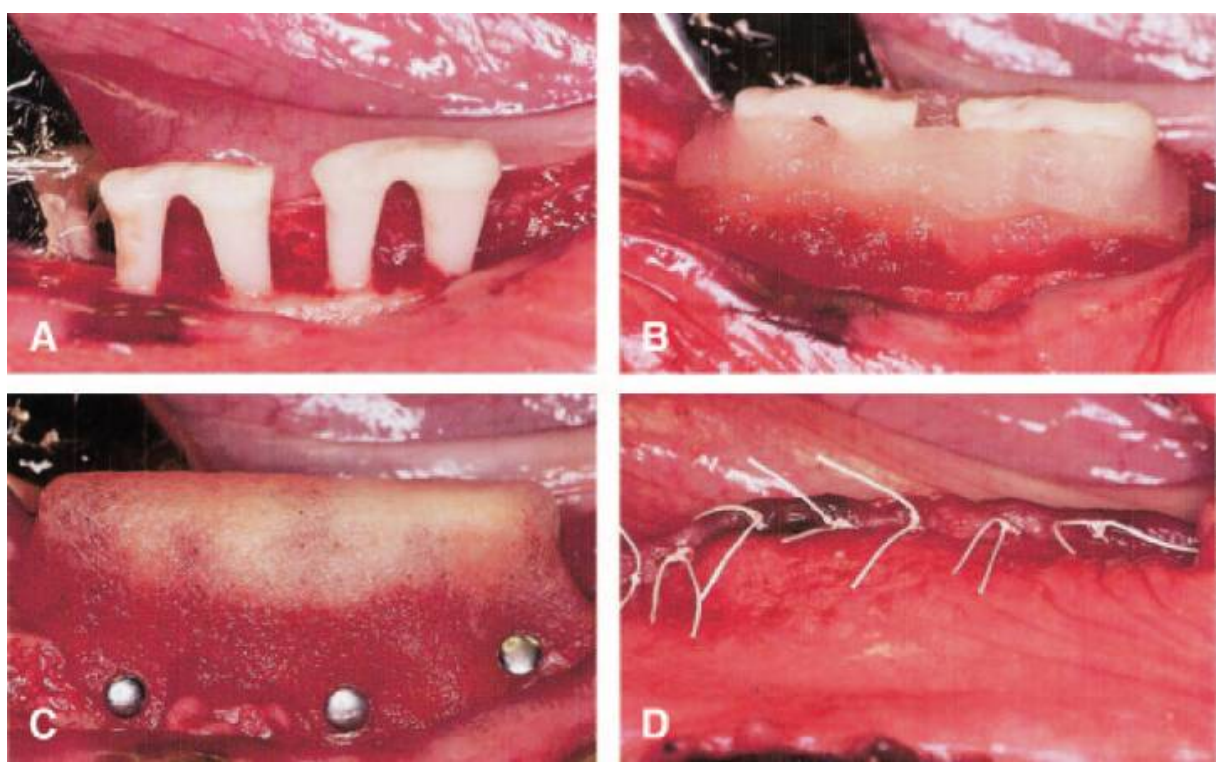

Figure I.

Mandibular jaw quadrant with surgically induced, critical size, discriminating, supraalveolar periodontal defect $(\boldsymbol{A})$. The defect is implanted with rhBMP-2/Hy (B) and a macroporous PGA-TMC membrane is placed over the teeth and the rhBMP-2/Hy construct and secured with stainless steel tacks $(\boldsymbol{C})$. The mucogingival flaps are then advanced to cover the teeth and implanted biomaterials, and sutured (D).
rhBMP-2/Hyaluronan Construct

rhBMP-2" (purified rhBMP-2 >98\%) was formulated in storage-stable buffer"l at a concentration of $0.2 \mathrm{mg} / \mathrm{ml}$ surgical implant volume. A bioabsorbable non-woven hyaluronic acid ester" (Hy; non-woven felt) was used for drug delivery in jaw quadrants receiving rhBMP-2 (Fig. 1). Four strips of the Hy biomaterial, each measuring $28 \times 10 \times 1.5 \mathrm{~mm}$, were cut from a larger piece of sterile material. Using a sterile syringe, $2.0 \mathrm{ml}$ of $0.2 \mathrm{mg} / \mathrm{mL}$ rhBMP-2 solution was withdrawn and uniformly dispensed over the surface of the $4 \mathrm{Hy}$ strips. Following a minimum 10-minute binding period, the rhBMP-2 soak-loaded Hy strips were layered within the defect space, the interdental space, and in each furcation.

\section{Surgical Protocol}

Food was withheld the night before surgical procedures. The animals were premedicated with atropine (0.02 $\mathrm{mg} / \mathrm{kg} \mathrm{IM})$, buprenorphine $(0.04 \mathrm{mg} / \mathrm{kg} \mathrm{IM})$, and flunixin meglumine $(0.1 \mathrm{mg} / \mathrm{kg} \mathrm{IV})$. A prophylactic antibiotic (cefazolin; $22 \mathrm{mg} / \mathrm{kg}$ IV) was administered. General anesthesia was induced with diazepam $(0.2 \mathrm{mg} /$ $\mathrm{kg}$ IV) and ketamine (6 mg/kg IV). An endotracheal tube was placed and the animals were maintained on isoflurane gas ( $1 \%$ to $2 \%$ ) in $100 \%$ oxygen using positive pressure ventilation. A sterile catheter was placed and the animals received a slow constant rate infusion of lactated Ringer's solution ( 10 to $20 \mathrm{ml} / \mathrm{kg} /$ hour IV) to maintain hydration while anesthetized. Routine dental infiltration anesthesia with epinephrine was administered at the surgical sites.

The maxillary first, second, and third premolar teeth were surgically extracted. The maxillary fourth premolars were reduced in height to alleviate potential trauma from the maxillary teeth to the experimental mandibular sites postsurgery and exposed pulpal tissues were sealed.**

Supraalveolar, critical size, periodontal defects were created around the third and fourth mandibular premolar teeth in right and left jaw quadrants in each animal (Fig. 1). ${ }^{27}$ Briefly, buccal and lingual mucoperiosteal flaps were reflected following buccal and lingual sulcular incisions from the

W.L. Gore \& Associates, Inc., Flagstaff, AZ.

I Wyeth Research, Cambridge, MA.

\# Fidia Advanced Biopolymers, Abano Terme, Italy.

** Cavit, ESPE, Seefeld/Oberbayern, Germany. 
canine tooth to the second molar. The first and second premolar teeth were extracted, and the first molar teeth were amputated to the level of the surgically reduced alveolar crest. Alveolar bone was removed around the circumference of the remaining premolar teeth using chisels and water-cooled rotating burs. The root surfaces were instrumented with curets, chisels, and water-cooled rotating diamonds to remove the cementum. The crowns of the teeth were reduced to approximately $2 \mathrm{~mm}$ coronal to the cementoenamel junction (CEJ) and the cut surfaces smoothed. Exposed pulpal tissues were sealed. Clinical defect height, from the CEJ to the reduced alveolar crest, was $6 \mathrm{~mm}$ as measured with a periodontal probe.

\section{Wound Management}

The precut rhBMP-2/Hy constructs were surgically implanted in one jaw quadrant in each animal. Contralateral jaw quadrants received Hy soak-loaded with buffer (2 ml) without rhBMP-2 (split-mouth design).

Experimental conditions were alternated between left and right jaw quadrants in subsequent animals. Dome-shaped PGA-TMC membranes were subsequently installed over the rhBMP-2/Hy and Hy control constructs (Fig. 1). The membranes were fixed to the reduced alveolar bone with medical grade stainless steel tacks ${ }^{\dagger \dagger}$ designed for these applications. Following placement of the membranes, periostea were fenestrated at the base of the flaps to allow tension-free flap apposition. The flaps were advanced, flap margins being adapted 3 to $4 \mathrm{~mm}$ coronal to the PGATMC membranes and sutured. Intrasurgery photographs were taken prior to and immediately after placement of the barrier membrane and following wound closure.

\section{Postsurgery Protocol}

Animals were fed a canned soft dog food diet the first 14 days postsurgery. Thereafter, the animals received a standard laboratory diet soaked in warm water until thoroughly soft. The animals received postoperative analgesia (buprenorphine; $0.04 \mathrm{mg} / \mathrm{kg}$ IM QID) for 2 days postsurgery. A broad-spectrum antibiotic (enrofloxacin; $2.5 \mathrm{mg} / \mathrm{kg}$, IM, bid) was used for postsurgery infection control for 14 days. Plaque control was maintained by twice daily topical application of chlorhexidine $^{\ddagger \dagger}$ (chlorhexidine gluconate 20\%; $40 \mathrm{ml}$ of a $2 \%$ solution) until gingival suture removal, thereafter, once daily (Monday through Friday) until completion of the study.

Radiographs were obtained immediately postsurgery, and at $4,8,12,16$, and 24 weeks postsurgery. Gingival sutures were removed under sedation at approximately 10 days postsurgery. Observations of experimental sites with regards to gingival health, maintenance of suture line closure, edema, and evidence of tissue necrosis or infection were made daily until suture removal, and at least twice weekly thereafter and recorded. The animals were scheduled for euthanasia at 8 and 24 weeks postsurgery. Following euthanasia, teeth with surrounding soft and hard tissues were removed en bloc. Membranes were not removed during the healing interval unless indicated as a consequence of wound failure.

\section{Histological Processing and Evaluation}

The tissue blocks were fixed in $10 \%$ buffered formalin for 3 to 5 days. Following fixation and complete decalcification with $20 \%$ EDTA, ${ }^{28}$ specimens were washed in running tap water and subsequently processed using an automatic tissue processor. $\S \S$ Standard methods were followed and specimens were infiltrated and embedded in methylmethacrylate. ${ }^{29}$ Specimens were allowed to polymerize for 3 to 5 days at room temperature. Five $\mu \mathrm{m}$ sections ${ }^{\|\|}$were taken $100 \mu \mathrm{m}$ apart. All sections were stained with a modified Goldner's trichrome stain.

The most central stained section of each root of the third and fourth premolar tooth was identified by the size of the root canal. This section and the adjacent stained step-serial sections were subjected to histometric analysis. Thus, 3 subsequent step-serial sections, encompassing approximately $0.2 \mathrm{~mm}$ of the mid-portion of the mesial and the distal root for each premolar tooth, were used for analysis. Analysis was performed using incandescent and polarized light microscopy, "TI a microscope digital camera system, "Tी and a PC-based image analysis system"\# ${ }^{\# \#}$ by one calibrated investigator masked to the specific experimental conditions. The following measurements were recorded for the buccal and the lingual tooth surfaces for each section. Defect height: distance between apical extension of the root planing and the CEJ. Junctional epithelium: distance between gingival margin and apical termination of the junctional epithelium. Connective tissue repair: distance between apical termination of junctional epithelium and apical extension of the root planing. Cementum regeneration (height): distance between apical extension of the root planing and the coronal extension of a continuous layer of new cementum or cementum-like deposit on the planed root. Bone regeneration (height): distance between the apical extension of root planing and the coronal extension of regenerated alveolar bone along the planed root. Root resorption: combined linear heights of distinct resorption lacunae on the planed root. Ankylosis: combined linear heights of ankylotic union between the regenerated alveolar bone and the planed root.

\footnotetext{
$\dagger \dagger$ FRIOS Augmentation System, Friatec, Mannheim, Germany

$\ddagger \ddagger$ Xttrium Laboratories, Inc., Chicago, IL.

$\S \S$ Tissue-Tek, Sakura, Torrance, CA.

\|II Reichert Jung Polycut, Leica, Deerfield, IL.

II Olympus America, Inc., Melville, NY.

\#\# Media Cybernetic, Silver Spring, MD.
} 


\section{Data Analysis}

Summary statistics (means \pm SD) based on animal means for the experimental conditions were calculated using the selected step serial sections. Differences between experimental conditions were analyzed using paired $t$ tests.

\section{RESULTS}

\section{Clinical Observations}

One animal was euthanized 12 days postsurgery due to bilateral wound failure and subsequent infection of the implanted sites. A second animal was euthanized at 6 weeks due to a chronic fistula in the control site. Four animals were euthanized at 8 weeks, and 3 animals were euthanized at 24 weeks postsurgery. For the histologic and histometric analysis, data from the animals euthanized at 6 and 8 weeks postsurgery were pooled. Jaw quadrants receiving the PGA-TMC control experienced membrane exposure at various timepoints. Healing was generally uneventful in sites receiving the PGA-TMC/rhBMP-2 combination (Fig. 2). All sites remained intact; however, one site experienced late exposure.

\section{Radiographic Observations}

Radiographic observations at 4 weeks postsurgery presented no appreciable bone formation in both PGATMC control and PGA-TMC/rhBMP-2 treated sites.
Radiographic observations at 8 and 24 weeks postsurgery showed significant bone formation encompassing the top surface of teeth in sites receiving the PGA-TMC/rhBMP-2 combination (Fig. 3). The newly formed bone also filled the furcation areas. Two animals exhibited radiographic evidence of seromas in sites treated with PGA-TMC/rhBMP-2 at 8 weeks postsurgery that partially resolved at 24 weeks postsurgery. Jaw quadrants receiving the PGA-TMC control exhibited bone fill approximating $10 \%$ to $50 \%$ and $30 \%$ to $70 \%$ of the defect height at 8 and 24 weeks, respectively.

\section{Histologic Observations}

Limited alveolar bone regeneration was observed in all jaw quadrants receiving the PGA-TMC control at 8 weeks postsurgery (Fig. 4). In contrast, sites receiving the PGA-TMC/rhBMP-2 combination exhibited substantial bone regeneration encompassing approximately $70 \%$ of the defect height (Fig. 5). The newly formed bone was predominantly a mixture of lamellar and woven bone. Fatty marrow and fibrovascular tissue was also observed in sites receiving PGA-TMC/ rhBMP-2.

The newly formed bone defined a periodontal ligament space. New cementum approximating $10 \%$ and $40 \%$ of the defect height was observed in the sites receiving the PGA-TMC control and PGA-TMC/rhBMP2 , respectively. The newly formed periodontal attach-
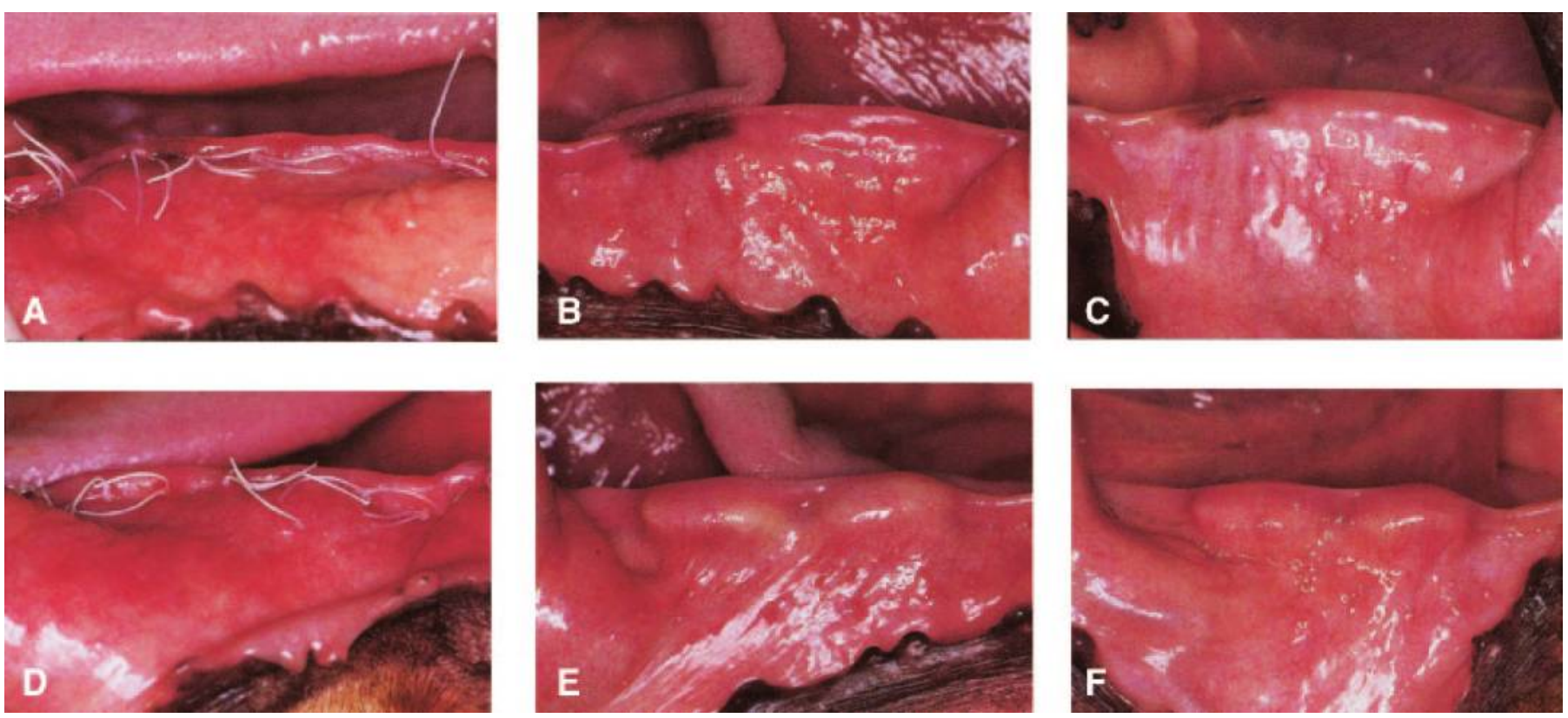

Figure 2.

Healing at suture removal at 7 days postsurgery in the jaw quadrant from Figure 1 implanted with the rhBMP-2/Hy construct and the macroporous PGA-TMC membrane (A) and in the contralateral jaw quadrant receiving the same treatment without rhBMP-2 (D; control). Note that the teeth are visible through the mucogingival tissues at 12 weeks $(\mathbf{E})$ and 24 weeks $(\boldsymbol{F})$ postsurgery in the control. They remain covered by a ridge firm to palpation in the jaw quadrant receiving rhBMP-2 at the same time points $(\mathbf{B}, \mathbf{C})$. 

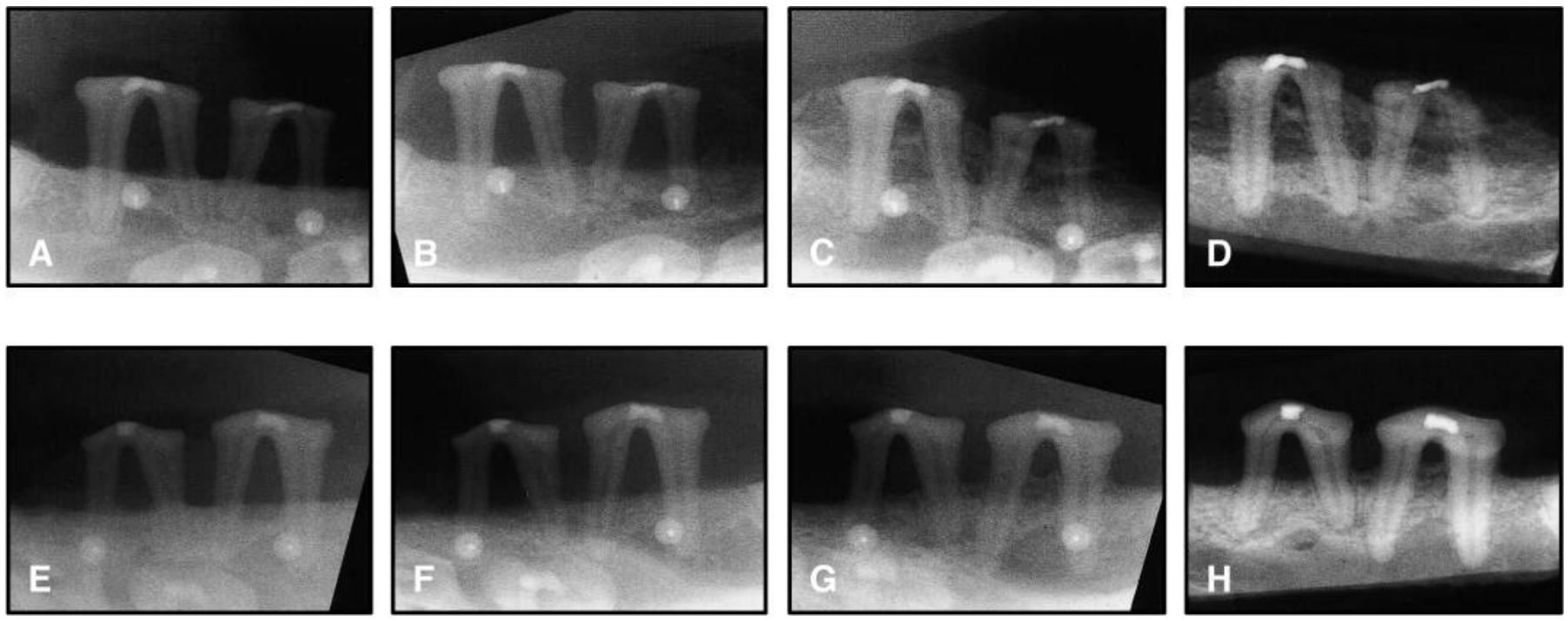

Figure 3.

Radiographic observations of contralateral jaw quadrants receiving PGA-TMC/rhBMP-2 combination (A, $\mathbf{B}, \boldsymbol{C}, \mathbf{D})$ or PGA-TMC membrane without $r h B M P-2(\mathbf{E}, \mathbf{F}, \mathbf{G}, \boldsymbol{H})$ from immediately postsurgery ( $A$ and $E)$, and at 4 (B and $F), 12$ (C and $G$ ), and 24 weeks (euthanasia) postsurgery (D and H). Note that bone regeneration may first be appreciated at the 12-week observation and that radiographic evidence of root resorption is present at 24 weeks in the jaw quadrant receiving PGA-TMC/rhBMP-2. Bone formation is restricted to the immediate vicinity of the teeth in sites receiving the PGA-TMC membrane without rhBMP-2, whereas bone formation encompasses the entire defect area outlined by the PGA-TMC membrane in the jaw quadrant receiving the PGA-TMC/rhBMP-2 combination.

ment included a combination of parallel and functionally oriented fibers. Functionally oriented fibers were a predominant finding in sites receiving the PGA-TMC treatment without rhBMP-2.

Ankylosis was a common finding in the CEJ area in sites receiving PGA-TMC/rhBMP-2. Root resorption of surface erosion character was observed in almost all sites. Undermining root resorption was observed without predilection to the applied treatment. Seroma formation was not observed in the 8-week specimens.

There were no traces of the Hy biomaterial in any site at 8 weeks postsurgery. In contrast, the PGA-TMC membrane remained intact in all sites. The host tissue response to the PGA-TMC material appeared relatively benign and was composed largely of fibrovascular elements in direct contact with the fibers comprising the material structure. When present, inflammatory elements were composed of non-foamy macrophages or multinucleated cells in direct contact with the material. Inflammatory infiltrates were localized to the material surface and were not diffuse in the surrounding tissue. Bone formation frequently approximated and incorporated the membrane structure in sites receiving PGA-TMC/rhBMP2. In one site, bone formation was also observed immediately outside the boundaries of the membrane.

Bone formation approximated $90 \%$ and $40 \%$ of the defect height in sites receiving PGA-TMC/rhBMP-2 and the PGA-TMC membrane without rhBMP-2, respectively, at 24 weeks postsurgery (Figs. 6 and 7). Newly formed bone represented a mixture of lamellar and woven bone. Fatty marrow was the predominant observation in sites receiving rhBMP-2 and fibrovascular tissue in sites receiving the PGA-TMC device without rhBMP-2.

Cementum regeneration approximated one-third of the defect height following both treatments. Jaw quadrants implanted with PGA-TMC/rhBMP-2 exhibited parallel-oriented fibers approximating the root surface (not shown). In contrast, sites implanted with PGA-TMC alone exhibited functionally oriented fibers inserting into the newly formed cementum (Fig. 6).

Ankylosis including the CEJ area and other aspects of the root surface was observed in sites receiving PGA-TMC/rhBMP-2 (Fig. 7). In contrast, sites without rhBMP-2 exhibited limited, if any, ankylosis. Root resorption of surface erosion character was a common finding following both protocols. Seroma formation was observed in one jaw quadrant receiving PGATMC/rhBMP-2 (not shown). There were no traces of residual PGA-TMC biomaterial in any site at the 24week observation interval.

\section{Histometric Analysis}

The histometric analysis is presented in Tables 1 through 4. Regeneration of alveolar bone was significantly enhanced in sites receiving the PGA-TMC/ rhBMP-2 combination compared to control $(3.8 \pm 1.3$ versus $0.7 \pm 0.5 \mathrm{~mm}$ at 8 weeks and $4.6 \pm 0.8$ versus $2.1 \pm 0.4 \mathrm{~mm}$ at 24 weeks, respectively; $P<0.05$ ). 

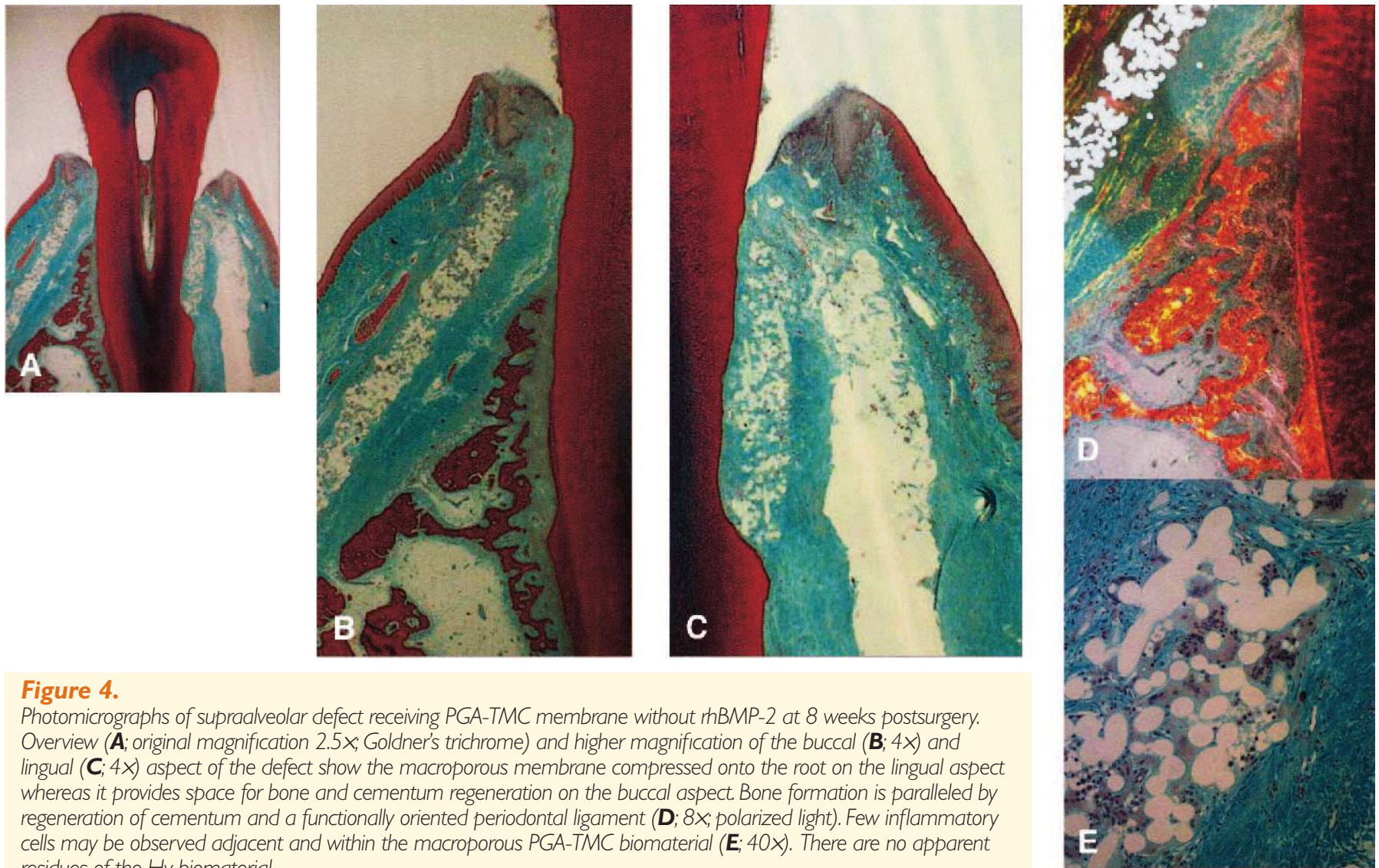

Figure 4.

Photomicrographs of supraalveolar defect receiving PGA-TMC membrane without rhBMP-2 at 8 weeks postsurgery. Overview (A; original magnification 2.5x; Goldner's trichrome) and higher magnification of the buccal $(\mathbf{B} ; 4 x)$ and lingual $(\mathbf{C} ; 4 X)$ aspect of the defect show the macroporous membrane compressed onto the root on the lingual aspect whereas it provides space for bone and cementum regeneration on the buccal aspect. Bone formation is paralleled by regeneration of cementum and a functionally oriented periodontal ligament (D; 8x; polarized light). Few inflammatory cells may be observed adjacent and within the macroporous PGA-TMC biomaterial (E; 40X). There are no apparent residues of the Hy biomaterial.

Cementum regeneration was significantly increased in sites receiving PGA-TMC/rhBMP-2 compared to those receiving the PGA-TMC control at 8 weeks $(2.1 \pm$ 1.0 versus $0.7 \pm 0.4 \mathrm{~mm}$, respectively; $P<0.01)$. Similar amounts of cementum regeneration were observed for the PGA-TMC/rhBMP-2 and the PGA-TMC control treatment at 24 weeks $(1.3 \pm 0.5$ versus $1.7 \pm 1.0 \mathrm{~mm}$, respectively; $P>0.05)$. Functionally oriented fibers were rare observations in sites receiving PGA-TMC/ rhBMP-2. In contrast, sites implanted with the macroporous PGA-TMC device characteristically showed functionally oriented fibers.

Ankylosis was significantly increased in sites receiving PGA-TMC/rhBMP-2 compared to sites receiving the PGA-TMC control. Root resorption of surface erosion character was observed in all animals.

\section{DISCUSSION}

The objective of this study was to evaluate regeneration of alveolar bone and periodontal attachment and to evaluate the biomaterial reaction following surgical implantation of a space-providing, bioabsorbable, macroporous PGA-TMC membrane combined with a rhBMP-2 construct in a discriminating onlay defect model. Contralateral critical size, supraalveolar periodontal defects in 9 beagle dogs received the dome- shaped PGA-TMC membrane with or without rhBMP2/Hy. Animals were euthanized at 8 and 24 weeks postsurgery for histologic and histometric analysis.

The PGA-TMC membrane appeared to be suitable biomaterial for bone augmentation procedures. At 8 weeks, the PGA-TMC membrane remained apparently intact and bone formation frequently approximated and incorporated into its micro- and macroporous structure in sites receiving rhBMP-2. The PGA-TMC membrane appeared completely resorbed at 24 weeks. Bone regeneration, including ankylosis, was significantly increased in sites receiving rhBMP-2 compared to controls. Similar and limited amounts of cementum regeneration were observed. There were notable differences in the nature of the periodontal attachment between rhBMP-2 and control sites. Functionally oriented fibers were commonly observed in control sites, however, they were a rare observation in rhBMP-2 sites.

There was a significant difference in coronal regrowth of alveolar bone in defect sites receiving PGATMC/rhBMP-2 compared to controls at both $8(67 \%$ versus $13 \%$ of the defect height) and 24 (85\% versus $38 \%$ of the defect height) weeks postsurgery. Similar observations were reported by Wikesjö et al. ${ }^{30}$ in this animal model using non-resorbable GTR membranes in conjunction with rhBMP-2. Regeneration of alveolar 

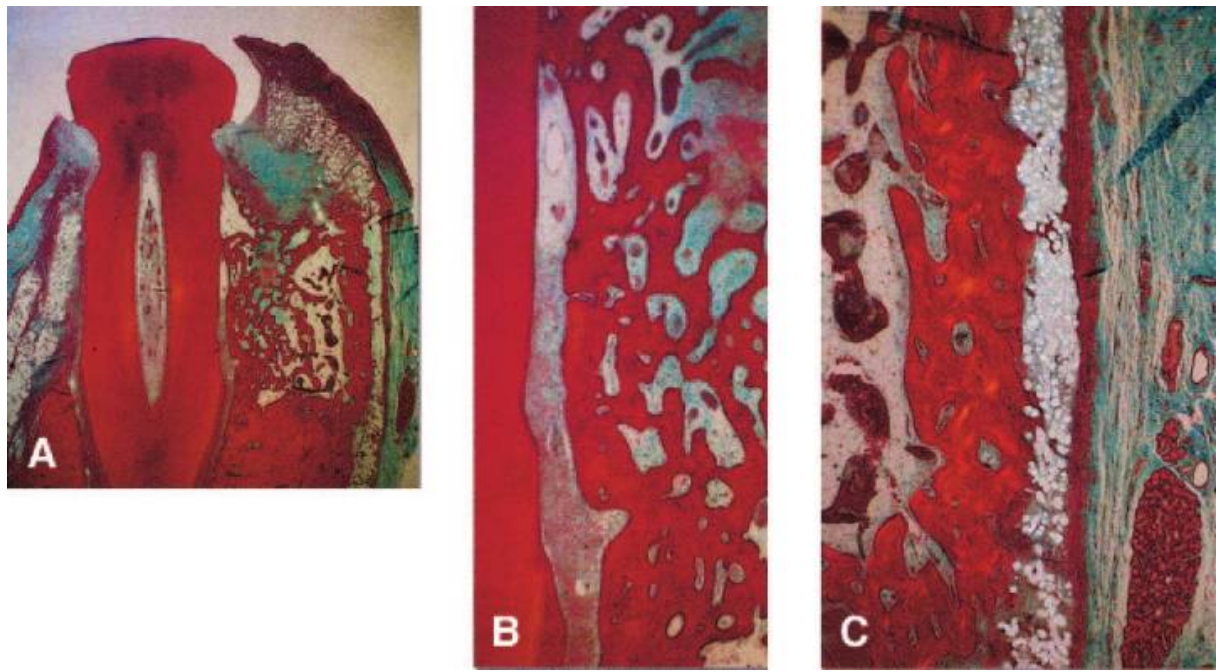

Figure 5.

Photomicrographs of supraalveolar defect receiving the PGA-TMC/rhBMP-2 combination at 8 weeks postsurgery. Overview (A; original magnification 2.5x; Goldner's trichrome) and higher magnification (B; $8 x)$ of the lingual aspect of the defect. The membrane compressed the root on the buccal aspect of the defect resulting in limited bone formation whereas space provision by the macroporous PGATMC membrane allows extensive bone formation on the lingual aspect Continuous cementum regeneration without a discernable periodontal ligament fusing with ankylotic bone in the more coronal aspect of the defect may be observed (B). Bone formation approaches and may be observed within the macroporous PGA-TMC biomaterial (C; $8 x)$. There are no apparent residues of the Hy biomaterial.
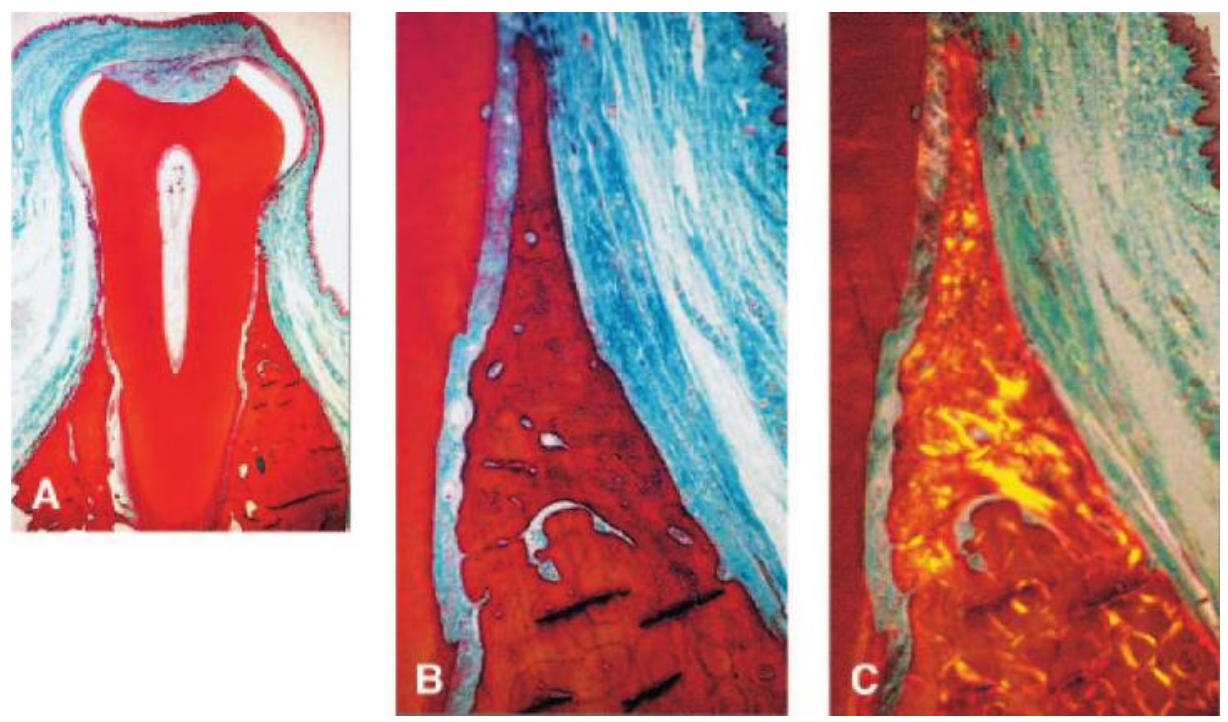

Figure 6.

Photomicrographs of supraalveolar defect receiving the PGA-TMC membrane without rhBMP-2 at 24 weeks postsurgery. Overview (A; original magnification 2.5x; Goldner's trichrome) and higher magnification of the lingual $(\mathbf{B} ; 8 x)$ aspect of the defect. Bone regeneration is paralleled by regeneration of cementum and a functionally oriented periodontal ligament (C; $8 x$; polarized light). There are no apparent residues of the Hy and PGA-TMC biomaterials.

bone averaged $4.8 \mathrm{~mm}$ (100\% of defect height) in sites receiving a macroporous ePTFE membrane combined

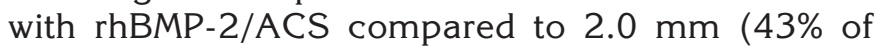
defect height) using the macroporous ePTFE mem- brane and buffer/ACS following an 8-week healing interval. Alveolar bone regeneration following surgical implantation of rhBMP-2/ACS without provisions for GTR approximated $75 \%$ of the defect height following an 8-week interval in a previous study using this animal model. ${ }^{18}$ Bone regeneration in surgical controls without rhBMP-2 averaged $0 \%$ of the defect height. Collectively, these data suggest that rhBMP-2 has a unique potential to induce clinically relevant regeneration of alveolar bone.

Cementum regeneration averaged $37 \%$ and $13 \%$ of the defect height, respectively, in sites receiving PGA-TMC/rhBMP-2 and the PGA-TMC control at 8 weeks postsurgery. At 24 weeks, the corresponding values were $24 \%$ and $31 \%$. Functionally oriented fibers, commonly observed in the PGATMC control, were rare observations in sites receiving rhBMP-2. Similar observations were made in our previous study evaluating the macroporous ePTFE membrane with or without rhBMP-2/ACS following an 8-week healing interval. ${ }^{30}$ Cementum regeneration approximated $33 \%$ and $22 \%$ of the defect height, respectively, in sites receiving the macroporous ePTFE membrane with or without rhBMP2/ACS. Additional studies have reported cementum regeneration averaging less than $10 \%$ of the defect height in sites receiving rhBMP-2/ACS in this animal model also using an 8-week healing interval. ${ }^{18}$ Cementum regeneration in control sites averaged $0 \%$ of the defect height. Cementum regeneration has also been evaluated in the critical size supraalveolar periodontal defect model following guided tissue regeneration. Sigurdsson et al. reported cementum regeneration including functionally oriented fibers averaging $41 \%$ of the defect height in sites receiving an occlusive ePTFE membrane at 8 weeks postsurgery. 4,5 Cementum regeneration in surgical controls averaged $1 \%$ of the defect height. Recently 
cementum regeneration was evaluated following surgical installation of space-providing occlusive and macroporous ePTFE membranes using an 8-week healing interval. ${ }^{10}$ Cementum regeneration including functional oriented fibers averaged $94 \%$ and $50 \%$ of the defect height in sites receiving occlusive and macroporous membranes, respectively. All together these observations suggest that rhBMP-2 may not play a decisive role in the regeneration of the periodontal attachment.

Ankylosis appears to be a considerable short-coming of the rhBMP-2/Hy technology for periodontal indications. Ankylosis commonly compromises healing following
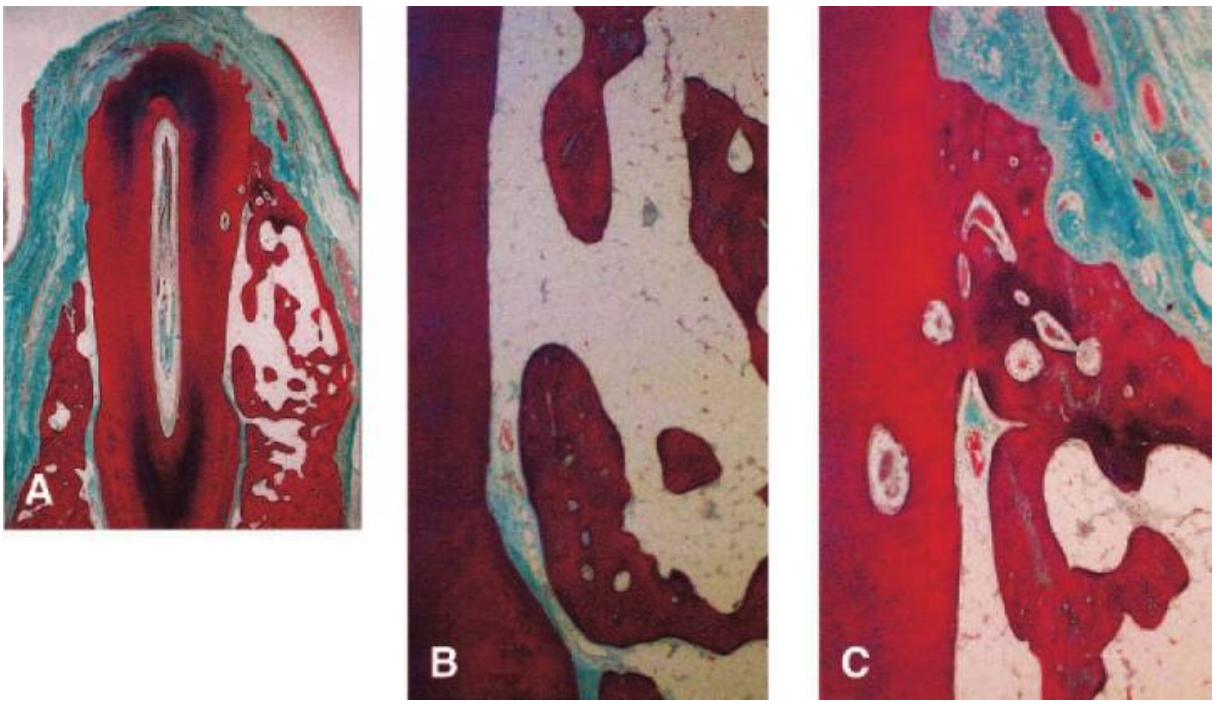

Figure 7.

Photomicrographs of supraalveolar defect receiving the PGA-TMC/rhBMP-2 combination at 24 weeks postsurgery. Overview (A; original magnification 2.5x; Goldner's trichrome) and higher magnification of the lingual ( $\mathbf{B}$ and $\mathbf{C} ; 8 \times$ ) aspect of the defect. Continuous cementum regeneration may be observed extending from the apical aspect of the defect (B) through the coronal extension of new bone forming an ankylotic union with the root (C). There is limited, if any, appreciable evidence of formation of a periodontal ligament. Fatty marrow is observed in immediate contact with the newly formed cementum. There are no apparent residues of the Hy and PGA-TMC biomaterials. application of other BMP technologies as well. Wikesjö et al. ${ }^{18,30,31}$ observed that cellular cementum extending from the apical extension of the defect often merged with ankylotic bone in supraalveolar periodontal defects implanted with rhBMP-2/ACS. Other studies using rhBMP$2^{5,16,17,22,32-35}$ or rhOP-1/BMP-7 ${ }^{36,37}$ in various carrier systems provide evidence of ankylosis in a variety of periodontal defects in rodent, canine, and non-human primate models. Ankylosis has not been a complication following surgical implantation of BMPs in the absence of extensive bone regeneration. ${ }^{36,38,39}$ In context, root resorption of surface erosion character as observed herein is a common finding following reconstructive periodontal surgery and is thus not unique to BMP technologies. ${ }^{40}$

Various biomaterials have been evaluated as candidate carriers for BMPs. These include collagen, decalcified bone matrix, hyaluronan, hydroxyapatite, calcium phosphates, a hydroxyapatitecollagen composite, various poly ( $\alpha$-hydroxy acids), and titanium. ${ }^{41}$ This study used a bioabsorbable non-woven hyaluronic acid ester non-woven felt to deliver rhBMP2 to periodontal sites. In a previous study, Hunt et al., ${ }^{21}$ using a large saddle-type alveolar ridge defect in the dog, showed that a Hy sponge supported significant bone induction by rhBMP-2 and that the Hy sponge alone possessed no apparent osteoconductive potential. Similar observations were made in the current study. The Hy non-woven felt was easy to prepare and exhibited favorable clinical characteristics upon soak

Table I.

Comparisons between Jaw Quadrants Receiving the PGA-TMC/rhBMP-2 Combination Versus the PGA-TMC Membrane without rhBMP-2 Following 8-Week Observation Interval $(\mathrm{N}=5$; means $\pm \mathrm{SD}$ in $\mathrm{mm})$

\begin{tabular}{|c|c|c|c|c|c|c|c|}
\hline Treatment & $\begin{array}{l}\text { Defect } \\
\text { Height }\end{array}$ & $\begin{array}{l}\text { Connective } \\
\text { Tissue Repair }\end{array}$ & $\begin{array}{l}\text { Junctional } \\
\text { Epithelium }\end{array}$ & $\begin{array}{c}\text { Cementum } \\
\text { Height }\end{array}$ & Bone Height & Ankylosis & $\begin{array}{c}\text { Root } \\
\text { Resorption }\end{array}$ \\
\hline $\begin{array}{r}\text { PGA-TMCl } \\
\text { rhBMP-2 }\end{array}$ & $5.7 \pm 0.1$ & $5.7 \pm 0.1$ & $0.0 \pm 0.0$ & $2.1 \pm 1.0$ & $3.8 \pm 1.3$ & $0.7 \pm 0.4$ & $0.7 \pm 0.3$ \\
\hline PGA-TM & $5.4 \pm 0.1$ & $2.8 \pm 0.6$ & $1.2 \pm 0.3$ & $0.7 \pm 0.4$ & $0.7 \pm 0.5$ & $0.0 \pm 0.0$ & $0.8 \pm 0.3$ \\
\hline$P$ value & 0.0077 & 0.0004 & 0.0014 & 0.0114 & 0.0017 & 0.0272 & 0.8906 \\
\hline
\end{tabular}


Table 2.

Frequency of Teeth Exhibiting Junctional Epithelium, Functionally Oriented Fibers, Ankylosis, Root Resorption, or Seroma Formation Following 8-Week Observation Interval

\begin{tabular}{|c|c|c|c|c|c|c|c|c|c|c|}
\hline \multirow[b]{2}{*}{ Animal } & \multicolumn{5}{|c|}{ PGA-TMC/rhBMP-2 } & \multicolumn{5}{|c|}{ PGA-TMC } \\
\hline & $\begin{array}{l}\text { Junctional } \\
\text { Epithelium }\end{array}$ & $\begin{array}{c}\text { Functionally } \\
\text { Oriented } \\
\text { Fibers }\end{array}$ & Ankylosis & $\begin{array}{c}\text { Root } \\
\text { Resorption }\end{array}$ & $\begin{array}{l}\text { Seroma } \\
\text { Formation }\end{array}$ & $\begin{array}{l}\text { Junctional } \\
\text { Epithelium }\end{array}$ & $\begin{array}{c}\text { Functionally } \\
\text { Oriented } \\
\text { Fibers }\end{array}$ & Ankylosis & $\begin{array}{c}\text { Root } \\
\text { Resorption }\end{array}$ & $\begin{array}{l}\text { Seroma } \\
\text { Formation }\end{array}$ \\
\hline I & $0 / 2$ & $0 / 2$ & $2 / 2$ & $2 / 2$ & $0 / 2$ & $2 / 2$ & $2 / 2$ & $0 / 2$ & $2 / 2$ & $0 / 2$ \\
\hline 2 & $0 / 2$ & $0 / 2$ & $1 / 2$ & $2 / 2$ & $0 / 2$ & $2 / 2$ & $2 / 2$ & $0 / 2$ & $2 / 2$ & $0 / 2$ \\
\hline 3 & $0 / 2$ & $2 / 2$ & $2 / 2$ & $2 / 2$ & $0 / 2$ & $2 / 2$ & $2 / 2$ & $0 / 2$ & $2 / 2$ & $0 / 2$ \\
\hline 4 & $0 / 2$ & $1 / 2$ & $1 / 2$ & $2 / 2$ & $0 / 2$ & $2 / 2$ & $1 / 2$ & $0 / 2$ & $2 / 2$ & $0 / 2$ \\
\hline 5 & $0 / 2$ & $0 / 2$ & $2 / 2$ & $2 / 2$ & $0 / 2$ & $2 / 2$ & $2 / 2$ & $0 / 2$ & $2 / 2$ & $0 / 2$ \\
\hline Group & $0 / 10$ & $3 / 10$ & $8 / 10$ & $10 / 10$ & $0 / 10$ & $10 / 10$ & $9 / 10$ & $0 / 10$ & $10 / 10$ & $0 / 10$ \\
\hline$\%$ & 0 & 30 & 80 & 100 & 0 & 100 & 90 & 0 & 100 & 0 \\
\hline
\end{tabular}

Table 3.

Comparisons between Jaw Quadrants Receiving the PGA-TMC/rhBMP-2 Combination Versus the PGA-TMC Membrane without rhBMP-2 Following 24-Week Observation Interval $(\mathrm{N}=3$; means $\pm \mathrm{SD}$ in $\mathrm{mm})$

\begin{tabular}{lccccccc}
\hline Treatment & $\begin{array}{c}\text { Defect } \\
\text { Height }\end{array}$ & $\begin{array}{c}\text { Connective } \\
\text { Tissue Repair }\end{array}$ & $\begin{array}{c}\text { Junctional } \\
\text { Epithelium }\end{array}$ & $\begin{array}{c}\text { Cementum } \\
\text { Height }\end{array}$ & Bone Height & Ankylosis & $\begin{array}{c}\text { Root } \\
\text { Resorption }\end{array}$ \\
\hline $\begin{array}{r}\text { PGA-TMCl } \\
\text { rhBMP-2 }\end{array}$ & $5.4 \pm 0.1$ & $5.4 \pm 0.1$ & $0.0 \pm 0.0$ & $1.3 \pm 0.5$ & $4.6 \pm 0.8$ & $2.9 \pm 1.6$ & $0.3 \pm 0.1$ \\
PGA-TMC & $5.5 \pm 0.2$ & $4.9 \pm 0.6$ & $0.3 \pm 0.3$ & $1.7 \pm 1.0$ & $2.1 \pm 0.4$ & $0.1 \pm 0.1$ & $0.7 \pm 0.6$ \\
P value & 0.5960 & 0.2278 & 0.1976 & 0.6377 & 0.0280 & 0.0840 & 0.2825 \\
\hline
\end{tabular}

Table 4.

Frequency of Teeth Exhibiting Junctional Epithelium, Functionally Oriented Fibers, Ankylosis, Root Resorption, or Seroma Formation Following 24-Week Observation Interval

\begin{tabular}{|c|c|c|c|c|c|c|c|c|c|c|}
\hline \multirow[b]{2}{*}{ Animal } & \multicolumn{5}{|c|}{ PGA-TMC/rhBMP-2 } & \multicolumn{5}{|c|}{ PGA-TMC } \\
\hline & $\begin{array}{l}\text { Junctional } \\
\text { Epithelium }\end{array}$ & $\begin{array}{c}\text { Functionally } \\
\text { Oriented } \\
\text { Fibers }\end{array}$ & Ankylosis & $\begin{array}{l}\text { Root } \\
\text { Resorption }\end{array}$ & $\begin{array}{l}\text { Seroma } \\
\text { Formation }\end{array}$ & $\begin{array}{l}\text { Junctional } \\
\text { Epithelium }\end{array}$ & $\begin{array}{c}\text { Functionally } \\
\text { Oriented } \\
\text { Fibers }\end{array}$ & Ankylosis & $\begin{array}{c}\text { Root } \\
\text { Resorption }\end{array}$ & $\begin{array}{c}\text { Seroma } \\
\text { Formation }\end{array}$ \\
\hline 6 & $0 / 2$ & $0 / 2$ & $2 / 2$ & $2 / 2$ & $0 / 2$ & $1 / 2$ & $2 / 2$ & $0 / 2$ & $2 / 2$ & $0 / 2$ \\
\hline 7 & $0 / 2$ & $0 / 2$ & $2 / 2$ & $2 / 2$ & $2 / 2$ & $1 / 2$ & $2 / 2$ & $0 / 2$ & $2 / 2$ & $0 / 2$ \\
\hline 8 & $0 / 2$ & $0 / 2$ & $2 / 2$ & $2 / 2$ & $0 / 2$ & $0 / 2$ & $2 / 2$ & $2 / 2$ & $2 / 2$ & $0 / 2$ \\
\hline Group & $0 / 6$ & $0 / 6$ & $6 / 6$ & $6 / 6$ & $2 / 6$ & $2 / 6$ & $6 / 6$ & $2 / 6$ & $6 / 6$ & $0 / 6$ \\
\hline$\%$ & 0 & 0 & 100 & 100 & 33 & 33 & 100 & 33 & 100 & 0 \\
\hline
\end{tabular}


loading. The rhBMP-2/Hy construct maintained its volume following application to the large supraalveolar periodontal defects. The clinical and radiographic examinations showed that rhBMP-2/Hy implanted sites restored tissue contour and readily filled with bone. The radiographic and histometric examination suggested that rhBMP-2/Hy implanted sites exhibited bone density comparable to that of the immediate resident bone without obvious residues of the Hy biomaterial. These properties all point to Hy biomaterials as candidate carriers for rhBMP-2.

When rhBMP-2/ACS constructs have been applied as onlays in alveolar defects, bone formation has been limited probably due to compression of the construct by forces from or transmitted through the gingival flaps. ${ }^{22-25,31,42}$ Previous studies have used occlusive ePTFE membranes in conjunction with implantation of rhBMP-2 constructs; however, occlusive membranes have been shown to impair the bone inducing capacity of rhBMP-2. ${ }^{43,44}$ Proof-of-principle studies have evaluated the efficacy of space-providing macroporous ePTFE membranes to support bone formation by rhBMP-2/ACS (references 30, 31, 42, and unpublished data). The macroporous ePTFE technology significantly increased bone formation by rhBMP-2/ACS when used as an onlay for alveolar augmentation. The bioabsorbable, space-providing, macroporous PGA-TMC membrane used in our study was developed to advance this novel treatment concept towards clinical application. The PGA-TMC macroporous biomaterial remained intact at 8 weeks postsurgery. Bone formation frequently approximated and incorporated into the membrane structure in sites receiving rhBMP-2. A limited inflammatory reaction was occasionally observed associated with the PGATMC biomaterial. These observations suggest a role for the bioabsorbable, space-providing, macroporous PGA-TMC membrane as a biocompatible device to support and delineate BMP induced bone formation.

In summary, The space-providing, macroporous PGA-TMC membrane is resorbed within 24 weeks and associated with only a minimal inflammatory reaction, bone may form up to and within the membrane; the PGA-TMC membrane provides for bone and cementum regeneration with a functionally oriented periodontal ligament (guided tissue regeneration); substantially increased bone formation occurs following implantation of rhBMP-2/Hy, geometry of bone formation being controlled by the PGA-TMC membrane; cementum regeneration with a functionally oriented periodontal ligament is rare in sites receiving rhBMP$2 / \mathrm{Hy}$; ankylosis is common following rhBMP-2/Hy induced bone formation; and limited root resorption mainly of surface erosion character appears common following use of the PGA-TMC membrane with or without rhBMP-2/Hy.

\section{CONCLUSIONS}

1) The PGA-TMC membrane appears a biocompatible, space-providing device suitable for GTR and for defining rhBMP-2 induced bone formation and 2) rhBMP-2 significantly enhances alveolar bone augmentation and soft tissue healing when combined with the PGA-TMC membrane.

\section{ACKNOWLEDGMENTS}

The authors thank Mary Stevens and Janet Golden, Wyeth Research, Cambridge, Massachusetts, for the histotechnical preparations; Rachel G. Sorensen, Clinical Scientist, Clinical Research and Development, Wyeth Research, for insightful review of the manuscript; and Dr. Melanie Manning and Tim Dombrowski, W.L. Gore \& Associates, Inc., Flagstaff, Arizona, for outstanding veterinary and technical animal care. Robert C. Thomson, Alonzo D. Cook, and W. Ross Hardwick are Senior Scientists at W.L. Gore E Associates, Inc. John M. Wozney is Assistant Vice President, Musculoskeletal Sciences, at Wyeth Research.

\section{REFERENCES}

1. Scantlebury TV. 1982-1992: A decade of technology development for guided tissue regeneration. JPeriodontol 1993;64:1129-1137.

2. Hardwick R, Scantlebury TV, Sanchez R, Whitley N, Ambruster J. Membrane design criteria for guided bone regeneration of the alveolar ridge. In: Buser D, Dahlin C, Schenk RK, eds. Guided Bone Regeneration in Implant Dentistry. Chicago: Quintessence Publishing Co, Inc.; 1994:101-136.

3. Haney JM, Nilvéus RE, McMillan PJ, Wikesjö UME. Periodontal repair in dogs: Expanded polytetrafluoroethylene barrier membranes support wound stabilization and enhance bone regeneration. J Periodontol 1993;64: 883-890.

4. Sigurdsson TJ, Hardwick R, Bogle GC, Wikesjö UME. Periodontal repair in dogs: Space provision by reinforced ePTFE membranes enhances bone and cementum regeneration in large supraalveolar defects. $\underline{J \text { Periodon- }}$ tol 1994;65:350-356.

5. Sigurdsson TJ, Tatakis DN, Lee MB, Wikesjö UME. Periodontal regenerative potential of space providing expanded polytetrafluoroethylene membranes and recombinant human bone morphogenetic proteins. $\underline{J}$ Periodontol 1995;66:511-521.

6. Trombelli L, Lee MB, Promsudthi A, Guglielmoni PG, Wikesjö UME. Periodontal repair in dogs: Histologic observations of guided tissue regeneration with a prostaglandin $\mathrm{E}_{1}$ analog/methacrylate composite. $\underline{\mathrm{JClin}}$ Periodontol 1999;26:381-387.

7. Schenk RK. Bone regeneration: Biologic basis. In: Buser D, Dahlin C, Schenk RK, eds. Guided Bone Regeneration in Implant Dentistry. Chicago: Quintessence Publishing Co, Inc.; 1994:49-100.

8. Karaki R, Kubota K, Hitaka M, Yamaji S, Kataoka R, Yamamoto $H$. Effect of gum-expanding mesh on the osteogenesis in surgical bony defect. J Jpn Assoc Periodontol 1984;26:516-522.

9. Zellin G, Linde A. Effects of different osteopromotive 
membrane porosities on experimental bone neogenesis in rats. Biomaterials 1996;17:695-702.

10. Wikesjö UME, Lim WH, Thomson RC, Hardwick WR. Periodontal repair in dogs: Gingival tissue exclusion, a critical requirement for guided tissue regeneration? $J$ Clin Periodontol 2003; in press.

11. Selvig KA, Nilvéus RE, Fitzmorris L, Kersten B, Khorsandi SS. Scanning electron microscopic observations of cell populations and bacterial contamination of membranes used for guided periodontal tissue regeneration in humans. J Periodontol 1990;61:515-520.

12. Selvig KA, Kersten BG, Chamberlain AD, Wikesjö UME, Nilvéus RE. Regenerative surgery of intrabony periodontal defects using ePTFE barrier membranes: Scanning electron microscopic evaluation of retrieved membranes versus clinical healing. J Periodontol 1992;63: 974-978.

13. Trombelli L, Kim C-K, Zimmerman GJ, Wikesjö UME. Retrospective analysis of factors related to clinical outcome of guided tissue regeneration procedures in intrabony defects. J Clin Periodontol 1997;24:366-371.

14. Tatakis DN, Promsudthi A, Wikesjö UME. Devices for periodontal regeneration. Periodontol 2000 1999;19: 59-73.

15. Tatakis DN, Trombelli L. Adverse effects associated with a bioabsorbable guided tissue regeneration device in the treatment of human gingival recession defects. A clinicopathologic case report. J Periodontol 1999;70:542547.

16. Ishikawa I, Kinoshita A, Oda S, Roongruanphol T. Regenerative therapy in periodontal diseases-Histological observations after implantation of rhBMP-2 in the surgically created periodontal defects in dogs. Dent Jpn 1994;31:141-146.

17. Sigurdsson TJ, Lee MB, Kubota K, Turek TJ, Wozney JM, Wikesjö UME. Periodontal repair in dogs: Recombinant human bone morphogenetic protein-2 significantly enhances periodontal regeneration. J Periodontol 1995; 66:131-138.

18. Wikesjö UME, Guglielmoni PG, Promsudthi A, et al. Periodontal repair in dogs: Effect of rhBMP-2 concentration on regeneration of alveolar bone and periodontal attachment. J Clin Periodontol 1999;26:392-400.

19. Selvig KA, Wikesjö UME, Sorensen RG, Wozney JM. Bone repair following rhBMP-2 stimulated periodontal regeneration. J Periodontol 2002;73:1020-1029.

20. Sigurdsson TJ, Nguyen S, Wikesjö UME. Alveolar ridge augmentation with rhBMP-2 and bone-to-implant contact in induced bone. Int J Periodontics Restorative Dent 2001;21:461-473.

21. Hunt DR, Jovanovic SA, Wikesjö UME, Wozney JM, Bernard GW. Hyaluronan supports rhBMP-2 induced bone reconstruction of advanced alveolar ridge defects in dogs. A pilot study. J Periodontol 2001;72:651-658.

22. Sigurdsson TJ, Nygaard L, Tatakis DN, et al. Periodontal repair in dogs: Evaluation of rhBMP-2 carriers. Int J Periodontics Restorative Dent 1996;16:525-537.

23. Sigurdsson TJ, Fu E, Tatakis DN, Rohrer MD, Wikesjö UME. Bone morphogenetic protein-2 enhances periimplant bone regeneration and osseointegration. Clin Oral Implants Res 1997;8:367-374.

24. Tatakis DN, Koh A, Jin L, Wozney JM, Rohrer MD, Wikesjö UME. Peri-implant bone regeneration using
rhBMP-2/ACS in a canine model: A dose-response study. $J$ Periodont Res 2002;37:93-100.

25. Barboza EP, Leite Duarte ME, Geolás L, Sorensen RG, Riedel GE, Wikesjö UME. Ridge augmentation following implantation of recombinant human bone morphogenetic protein-2 in the dog. J Periodontol 2000;71:488-496.

26. Hardwick R, Hayes BK, Flynn C. Devices for dentoalveolar regeneration: An up-to-date literature review. J Periodontol 1995;66:495-505.

27. Wikesjö UME, Kean CJC, Zimmerman GJ. Periodontal repair in dogs: Supraalveolar defect models for evaluation of safety and efficacy of periodontal reconstructive therapy. J Periodontol 1994;65:1151-1157.

28. Luna LG. Histologic Methods and Color Atlas of Special Stains and Tissue Artifacts. Gaithersburg, MD: American Histolab, Inc., Publications Division; 1992:113.

29. Schenk RK, Olah AJ, Herrmann W. Preparation of calcified tissues for light microscopy. In: Dickson GR, ed. Methods of Calcified Tissue Preparation. Amsterdam: Elsevier Science Publishers BV; 1984:1-42.

30. Wikesjö UME, Xiropaidis AV, Thomson RC, Cook AD, Selvig KA, Hardwick WR. Periodontal repair in dogs: rhBMP-2 significantly enhances bone formation under provisions for guided tissue regeneration. J Clin Periodontol 2003; in press.

31. Wikesjö UME, Xiropaidis AV, Thomson RC, Cook AD, Selvig KA, Hardwick WR. Periodontal repair in dogs: Space-providing ePTFE devices increase rhBMP-2 induced bone formation. J Clin Periodontol 2003; in press.

32. King GN, King N, Chruchley AT, Wozney JM, Hughes FJ. Recombinant human bone morphogenetic protein-2 promotes wound healing in rat periodontal fenestration defects. J Dent Res 1997;76:1460-1470.

33. King GN, King N, Hughes FJ. Effect of two delivery systems for recombinant human bone morphogenetic protein-2 on periodontal regeneration in vivo. J Periodont Res 1998;33:226-236.

34. King GN, King N, Hughes FJ. The effect of root surface demineralization on bone morphogenetic protein-2induced healing of rat periodontal fenestration defects. J Periodontol 1998;69:561-570.

35. King GN, Hughes FJ. Effects of occlusal loading on ankylosis, bone, and cementum formation during bone morphogenetic protein-2-stimulated periodontal regeneration in vivo. J Periodontol 1999;70:1125-1135.

36. Ripamonti $U$, Heliotis M, Rueger DC, Sampath TK. Induction of cementogenesis by recombinant human osteogenic protein-1 (hop-1/bmp-7) in the baboon (Papio ursinus). Short communication. Arch Oral Biol 1996;41: 121-126.

37. Giannobile WV, Ryan S, Shih M-S, Su DL, Kaplan PL, Chan TCK. Recombinant human osteogenic protein-1 (OP-1) stimulates periodontal wound healing in Class III furcation defects. J Periodontol 1998;69:129-137.

38. Kinoshita A, Oda S, Takahashi K, Yokota S, Ishikawa I. Periodontal regeneration by application of recombinant human bone morphogenetic protein-2 to horizontal circumferential defects created by experimental periodontitis in beagle dogs. J Periodontol 1997;68:103-109.

39. Choi S-H, Kim C-K, Cho K-S, et al. Effect of recombinant human bone morphogenetic protein-2/absorbable collagen sponge (rhBMP-2/ACS) on healing in 3-wall intrabony defects in dogs. JPeriodontol 2002;73:63-72. 
40. Wikesjö UME, Selvig KA. Periodontal wound healing and regeneration. Periodontol 2000 1999;19:21-39.

41. Wikesjö UME, Sorensen RG, Wozney JM. Augmentation of alveolar bone and dental implant osseointegration. Clinical implications of studies with rhBMP-2. A comprehensive review. J Bone Joint Surg Am 2001;83-A Suppl. 1(Pt 2):S136-S145.

42. Wikesjö UME, Qahash M, Thomson RC, et al. Space providing ePTFE devices define rhBMP-2 induced alveolar augmentation at dental implants. Clin Implant Dent Relat Res 2002; accepted for publication.

43. Cochran DL, Schenk R, Buser D, Wozney JM, Jones AA. Recombinant human bone morphogenetic protein2 stimulation of bone formation around endosseous dental implants. J Periodontol 1999;70:139-150.

44. Zellin G, Linde A. Importance of delivery systems for growth-stimulatory factors in combination with osteopromotive membranes. An experimental study using rhBMP-2 in rat mandibular defects. Biomed Mater Res 1997;35:181-190.
Correspondence: Dr. Ulf M.E. Wikesjö, Laboratory for Applied Periodontal and Craniofacial Regeneration, Temple University School of Dentistry, 3223 Broad St., Philadelphia, PA 19140. E-mail: uwikesjo@temple.edu.

Accepted for publication November 15, 2002. 